\title{
Effect of a Cocatalyst on a Photoanode in Water Splitting: A Study of Scanning Electrochemical Microscopy
}

Zehui Yu, ${ }^{\dagger}, l$ Qikang Huang, ${ }^{\dagger, \S, l}$ Xingxing Jiang, ${ }^{\dagger}$ Xiaowei Lv, ${ }^{\dagger}$ Xin Xiao, ${ }^{\dagger}$ Mingkui Wang, ${ }^{\dagger}$ Yan Shen, ${ }^{\dagger, *}$ Gunther Wittstock ${ }^{\ddagger}, *$

† Wuhan National Laboratory for Optoelectronics, University of Science and Technology, Wuhan 430074, P. R. China

‡ Carl von Ossietzky University of Oldenburg, School of Mathematics and Science Chemistry Department, D-26111 Oldenburg, Germany

$\S$ China-EU Institute for Clean and Renewable Energy, Huazhong University of Science and Technology, Wuhan 430074, P. R. China

I These authors contributed equally to this work.

\section{Contents:}

\section{SI-1 Experimental section}

SI-2 UV-visible absorption spectroscopy measurement and Mott-Schottky analysis SI-3 Equations used to describe normalized approach curve in SECM feedback mode

SI-4 Detailed procedures for deducing the regenerating kinetics of photoanode SI-5 Normalized approach curves towards FTO/BiVO 4 and FTO/BiVO $/ \mathrm{NiFe}$ LDH film in dark

SI-6 Plots of $\ln \left(k_{\text {eff }}\right)$ vs $\eta$ for the photoanodes for $\mathrm{FTO} / \mathrm{BiVO}_{4}$ and FTO/BiVO $4 / \mathrm{NiFe}^{\mathrm{LDHH}}$ film in dark

SI-7 Calculated data from SECM measurement

SI-8 UV-visible absorption spectroscopy measurement

\section{References}




\section{SI-1 Experimental section}

\section{Materials and apparatus}

Bismuth nitrate pentahydrate and vanadyl acetylacetonate [VO(acac)2] were purchased from Aladdin. Sodium sulfate, potassium ferrocyanide, potassium ferricyanide, nickel nitrate hexahydrate, ammonium iron sulfate hexahydrate, cobalt nitrate, ruthenium chloride and absolute anhydrous ethanol were purchased from Shanghai Chemical Reagent Co. Ltd. All materials were employed in analytical grade without further purification. Milli-Q water $(18.2 \mathrm{M} \Omega \mathrm{cm})$ served as solvent to prepare aqueous solutions for electrochemical experiments. 0.1 M phosphate buffer solution (pH 7.0) containing 0.5 $\mathrm{M} \mathrm{Na}_{2} \mathrm{SO}_{4}$ was prepared freshly every day.

\section{Synthesis of $\mathrm{BiVO}_{4}$ electrodes}

$\mathrm{BiVO}_{4}$ was synthesized by two-step method as reported before. ${ }^{1,2}$ The first step was the preparation of BiOI. The $\mathrm{pH}$ of $0.4 \mathrm{M} \mathrm{KI}$ solution $(50 \mathrm{~mL})$ was adjusted to 1.7 by addition of $\mathrm{HNO}_{3}$ followed by addition of $\mathrm{Bi}\left(\mathrm{NO}_{3}\right)_{3} \cdot 5 \mathrm{H}_{2} \mathrm{O}$ to prepare a $40 \mathrm{mM}$ $\mathrm{Bi}\left(\mathrm{NO}_{3}\right)_{3}$ solution. This solution was mixed with $0.02 \mathrm{~L}$ of pure alcohol containing 0.23 M p-benzoquinone. Finally, BiOI was deposited with an electrochemical workstation (CHI-750D, Shanghai Chenhua, China) in a three-electrode cell with $1 \mathrm{~cm} \times 1 \mathrm{~cm}$ fluorine-doped tin oxide (FTO) (Lattice Solar Technology Co. LTD) as working electrode, $\mathrm{Ag} / \mathrm{AgCl}$ (filled with saturated $\mathrm{KCl}$ ) as reference electrode and a platinum wires as auxiliary electrode by applying $-0.1 \mathrm{~V}$ vs. Ag/AgCl for 5 min. The BiOI layer was then converted to $\mathrm{BiVO}_{4}$ by heating the electrode in a muffle furnace to $450{ }^{\circ} \mathrm{C}$ (heating rate $=2{ }^{\circ} \mathrm{C} \cdot \mathrm{min}^{-1}$ ) for $2 \mathrm{~h}$ after placing $50 \mu \mathrm{L}$ of $400 \mathrm{mM} \mathrm{VO}($ acac) 2 in dimethyl 
sulfoxide onto the surface of BiOI. Afterwards, the electrodes were immersed into $1 \mathrm{M}$ $\mathrm{NaOH}$ for $0.5 \mathrm{~h}$ with mild stirring to remove excess $\mathrm{V}_{2} \mathrm{O}_{5}$ from $\mathrm{BiVO}_{4}$ followed by washing the electrodes with DI water for 30 min.

\section{NiFe-LDH deposition}

The NiFe-LDH was synthetized as reported before ${ }^{3}$ in three-electrode configuration use for the BiOI deposition except that the working electrode was $\mathrm{BiVO}_{4}$-coated FTO slide whose preparation was described above. The NiFe-LDH was deposited at $0.5 \mathrm{~V}$ for $300 \mathrm{~s}$ from aqueous solution with $0.05 \mathrm{M}\left(\mathrm{NH}_{4}\right)_{2} \mathrm{Fe}\left(\mathrm{SO}_{4}\right)_{2}$ and $0.05 \mathrm{M} \mathrm{Ni}\left(\mathrm{NO}_{3}\right)_{2}$ (purged with $\mathrm{N}_{2}$ for $0.5 \mathrm{~h}$ ). Then the electrode was washed by DI water and dried at room temperature.

\section{Co-catalyst deposition}

CoPi was electrodeposited on $\mathrm{BiVO}_{4}$ photoanodes according to the reported procedures. ${ }^{4}$ The same three-electrode cell was used as for $\mathrm{NiFe-LDH}$ with $\mathrm{BiVO}_{4}-$ coated FTO as the working electrode. The CoPi was deposited at $0.9 \mathrm{~V} \mathrm{vs.} \mathrm{Ag} / \mathrm{AgCl}$ for $300 \mathrm{~s}$ in a $0.1 \mathrm{M}$ potassium phosphate buffer $(\mathrm{pH} 7)$ with $0.5 \mathrm{mM}$ cobalt nitrate.

The $\mathrm{RuO}_{\mathrm{x}}$ was photoelectrodeposited on $\mathrm{BiVO}_{4}$-coated FTO in the three-electrode cell described above. According to the reports from Tsuji, ${ }^{5}$ the photo-electrodeposition was conducted in $5 \mathrm{mM} \mathrm{RuCl} 3(\mathrm{pH}$ 7) at $1.0 \mathrm{~V}$ vs. RHE for $400 \mathrm{~s}$ under AM 1.5 illumination. 

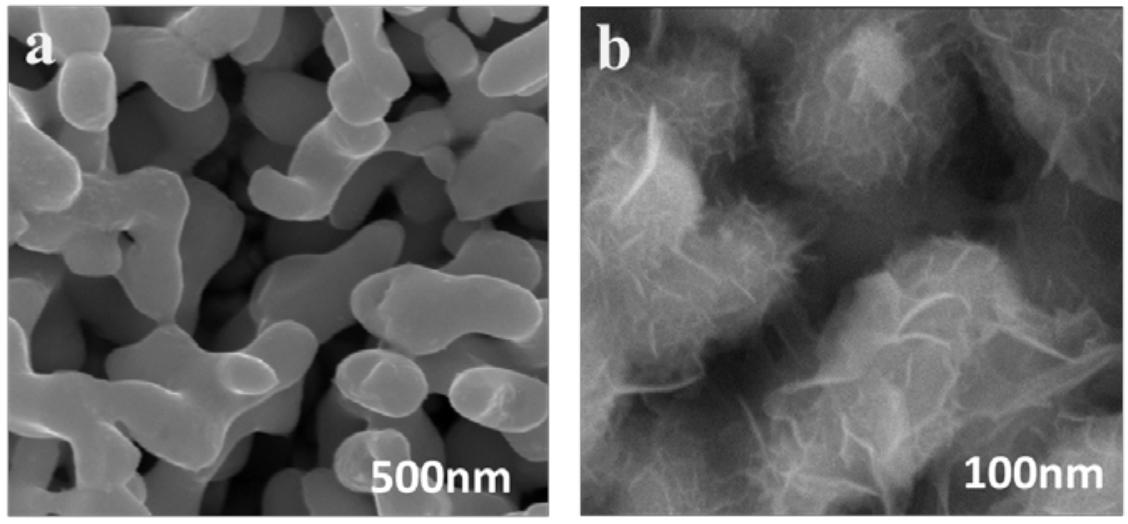

Figure S1. (a) SEM image of $\mathrm{BiVO}_{4}$, (b) SEM image of $\mathrm{BiVO}_{4} / \mathrm{NiFe}-\mathrm{LDH}$.

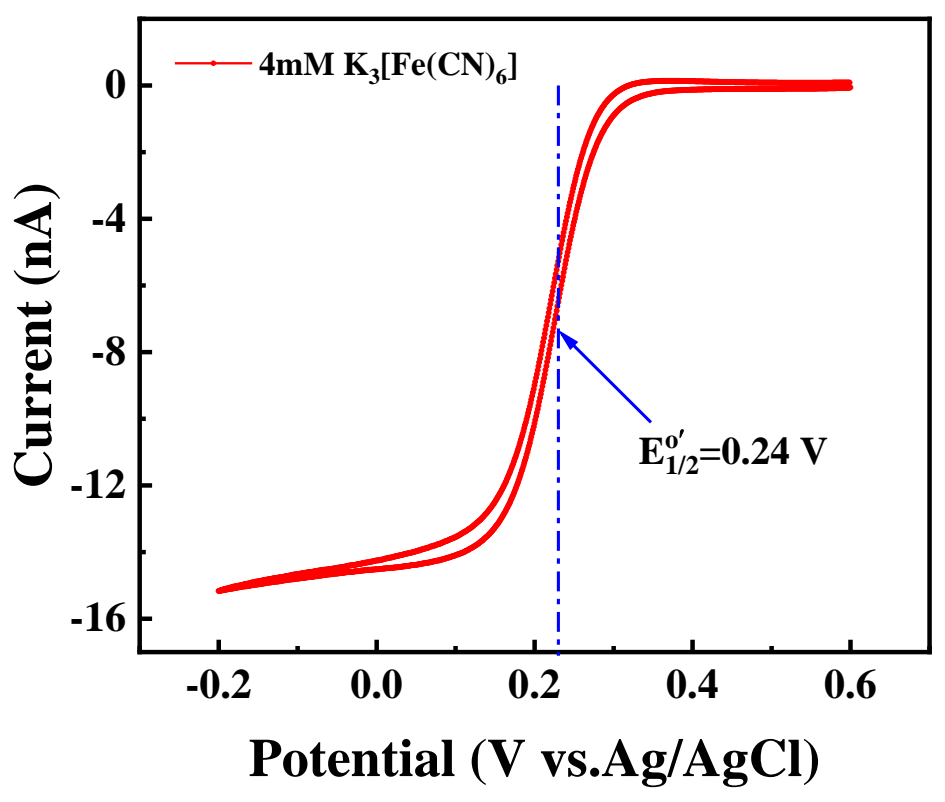

Figure S2. The CV of the microelectrode in $4 \mathrm{mM}\left[\mathrm{Fe}(\mathrm{CN})_{6}\right]^{3-}$ at a scan rate of $20 \mathrm{mV} \mathrm{s}^{-1}$.

The cyclic voltammogram (CV) of the Pt UME had a standard "S" shape (Figure S2) which can satisfy the experimental requirement. The current was recorded under steady-state diffusion and the scan rate was $20 \mathrm{mV} \cdot \mathrm{s}^{-1}$. The electrolyte used here was 4 $\mathrm{mM} \mathrm{K}_{3}\left[\mathrm{Fe}(\mathrm{CN})_{6}\right]$ with $0.1 \mathrm{M} \mathrm{KCl}$. 
SI-2 UV-visible absorption spectroscopy measurement and Mott-Schottky analysis
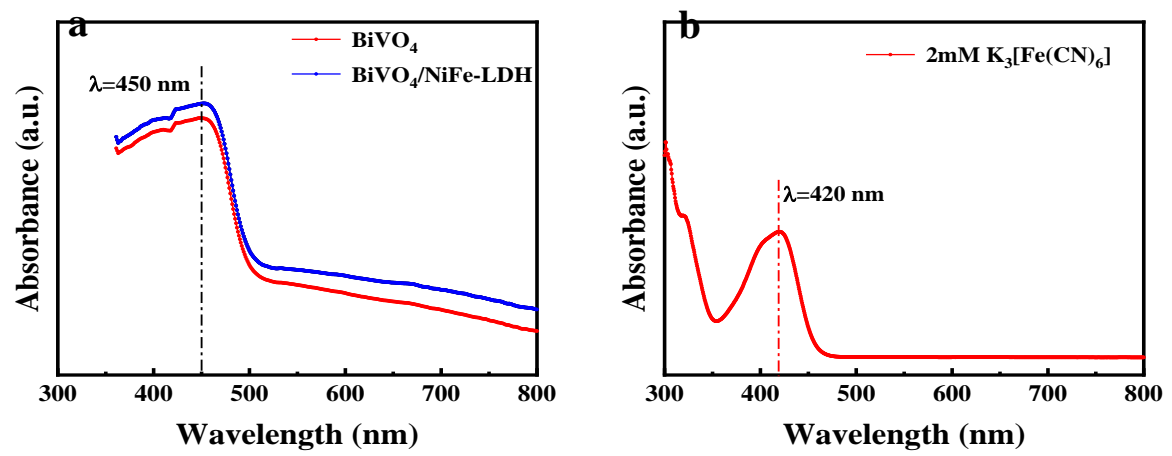

Figure S3. (a) UV-visible absorption spectroscopy of the $\mathrm{BiVO}_{4}$ and $\mathrm{BiVO}_{4} / \mathrm{NiFe}-\mathrm{LDH}$ samples. (b) UV-visible absorption spectroscopy of $\mathrm{K}_{3}\left[\mathrm{Fe}(\mathrm{CN})_{6}\right]$ solution.

It can be seen from the Figure S3(a) that the maximum light absorption of $\mathrm{BiVO}_{4}$ and $\mathrm{BiVO}_{4} / \mathrm{NiFe}-\mathrm{LDH}$ is around $450 \mathrm{~nm}$, which is the wavelength range of blue light. Therefore, blue light LED is selected as the photoelectric catalytic excitation light source in the subsequent SECM test.

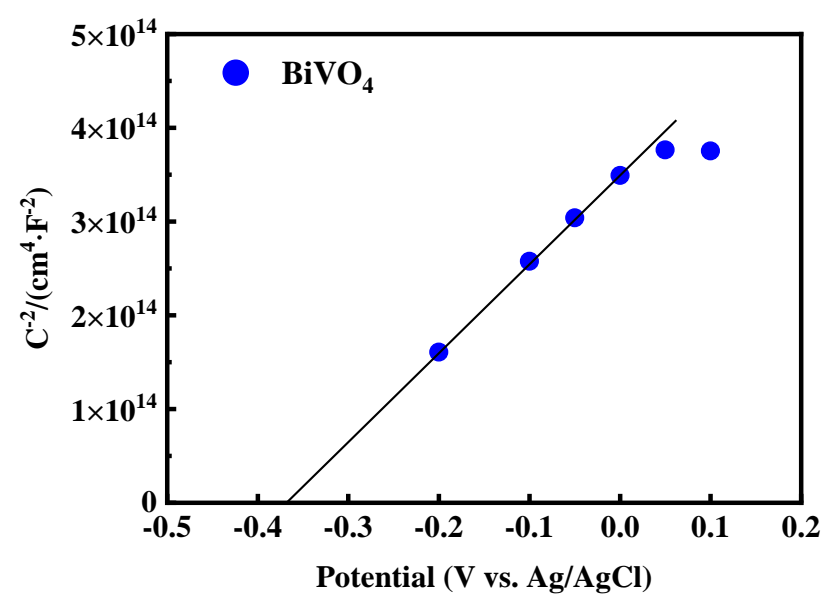

Figure S4. Mott-Schottky plot measured in the dark in $0.1 \mathrm{M}$ PBS $(\mathrm{pH}=7.0)$ solution for $\mathrm{BiVO}_{4}$ thin film sample.

It can be seen from the Figure $\mathbf{S} 4$ that the flat band potential $\left(\mathrm{V}_{\mathrm{FB}}\right)$ of $\mathrm{BiVO}_{4}$ is around $-0.37 \mathrm{~V}$ vs. Ag/AgCl. By calculating the slope of the line, we can get that the majority carrier density $(\mathrm{ND})$ is $2.13 \times 10^{15} \mathrm{~cm}^{-3}$. 


\section{SI-3 Equations used to describe normalized approach curve in SECM feedback mode.}

In this study SECM was employed to scrutinize interfacial reaction kinetics in photoelectrochemical water splitting with a feedback mode at the $\mathrm{BiVO}_{4} /$ electrolyte heterojunction through the reduction of the oxidized photoelectric catalyst cations. The basic concept of interest in connection with measurements at the photoanode/electrolyte is that of the UME feedback current. When the ultramicroelectrode is far from any surface, the UME current $i \mathrm{T, \infty}$ is determined by the number of electrons involved in the electrode reaction, the diffusion coefficient and the concentration of the electroactive reactants, and the radius of the UME. When the UME is close to a surface, the UME current $i_{\mathrm{T}}$ is perturbed by blockage of diffusion of $\mathrm{O}_{\mathrm{x}}$ to the UME by the substrate (assumption of reduction reaction onto the UME) and by reactions that occur at the substrate surface.

In this study, during the SECM measurement with feedback model, the UME current is determined by the reduction of $\mathrm{O}_{\mathrm{x}}$ in the solution in dark (the substrate can be considered as insulating electrode causing negative feedback). However, when light is shed onto the electrode, an active electrode, the Red generated by the UME can be converted to the oxidized state again via reactions on the active substrate electrode/electrolyte interface (the substrate can be considered as conducting electrode, i.e., positive feedback). Therefore, the feedback current is from the conversion of the mediator in the solution.

According to approach the curves ( $I_{\mathrm{T}}-L$ curve) on the UME, the approximate curvature of different substrates only reflects the electrochemical properties of the 
substrates, which is independent of probe radius, concentration of electroactive substances and diffusion coefficient. So, Lefrou and Cornut proposed an analytical function for the approach curve towards an insulating substrate and a conductive substrate. $^{6-8}$

$I_{T}(L, R G, \kappa)=I_{T}^{\text {cond }}\left(L+\frac{1}{\kappa}, R G\right)+\frac{I_{T}^{i n s}(L, R G)-1}{\left(1+2.47 R G^{0.31} L \kappa\right)\left(1+L^{0.006 R G+0.1} 13 \kappa^{-0.023 R G+0.91}\right)}$

For insulating substrate,

$I_{T}^{\text {ins }}(L, R G)=\frac{\left(\frac{2.08}{R G^{0.358}}\right)\left(L-\left(\frac{0.145}{R G}\right)\right)+1.585}{\left(\frac{2.08}{R G^{0.358}}\right)(L+0.00238 R G)+1.57+\left(\ln \frac{\mathrm{RG}}{L}\right)+(2 / \pi R G) \ln (1+(\pi R G / 2 L))}$

For conductive substrate,

$I_{T}^{\text {cond }}\left(L+\kappa^{-1}, R G\right)=\alpha(R G)+\frac{\pi}{4 \beta(R G) \arctan \left(\mathrm{L}+\kappa^{-1}\right)}+(1-\alpha(R G)-$ $\left.\frac{1}{2 \beta(R G)} \frac{2}{\pi} \arctan \left(L+\kappa^{-1}\right)\right)$

(Eq. S3)

$$
I_{T}=I_{S}\left(1-\frac{I_{T}^{\text {ins }}}{I_{T}^{\text {cond }}}\right)+I_{T}^{\text {ins }}
$$

$\alpha(R G)=\ln 2+\ln 2\left(1-\frac{2}{\pi} \arccos \left(\frac{1}{R G}\right)\right)-\ln 2\left(1-\left(\frac{2}{\pi} \arccos \left(\frac{1}{R G}\right)\right)^{2}\right)$

$\beta(R G)=1+0.639\left(1-\frac{2}{\pi} \arccos \left(\frac{1}{R G}\right)\right)-0.186\left(1-\left(\frac{2}{\pi} \arccos \left(\frac{1}{R G}\right)\right)^{2}\right)$

where, $R G$ is the ratio of the probe insulating glass shell radius to the platinum wire radius (that is 10 ), and $\kappa$ is the apparent charge transfer rate constant of the substrate. $I_{T}^{c o n d}$ is the diffusion-controlled mediator recycling at the sample ("positive feedback"), and $I_{T}^{\text {ins }}$ describes the current if no reaction occurs at the insulating sample ("negative 
feedback"). Therefore, the effective charge transfer rate constant of the substrate is further obtained as $k_{\text {eff }}\left(=\kappa D / r_{\mathrm{T}}, D\right.$ is the diffusion coefficient of the electroactive substance in the solution). When the probe approaches the surface of the substrate at open circuit potential, the $k_{\text {eff }}$ of the insulating substrate approaches a value of 0 and the $k_{\text {eff }}$ of the conductive substrate tends to an infinite number $\infty$. 
SI-4 Detailed procedures for deducing the regenerating kinetics of photoanode.

The following reaction mechanism for photocatalyst $\left(\mathrm{BiVO}_{4}\right)$ regeneration was developed under steady state SECM experiments for the dynamic equilibrium process of the charge transfer with $\left[\mathrm{Fe}(\mathrm{CN})_{6}\right]^{3-/}\left[\mathrm{Fe}(\mathrm{CN})_{6}\right]^{4-}$ as redox probe. ${ }^{9}$

$$
\begin{aligned}
& \mathrm{BiVO}_{4} / \mathrm{FTO}+h v \stackrel{\phi_{h v}}{\rightarrow} \mathrm{BiVO}_{4}^{*} / \mathrm{FTO} \\
& \mathrm{BiVO}_{4}^{*} / \mathrm{FTO} \stackrel{k_{i n}}{\rightarrow} \mathrm{BiVO}_{4}^{+} / \mathrm{FTO}+e_{\mathrm{CB}}^{-} \\
& \mathrm{BiVO}_{4}^{+} / \mathrm{FTO}+\left[\mathrm{Fe}(\mathrm{CN})_{6}\right]^{4-} \stackrel{k_{1}}{\rightarrow} \mathrm{BiVO}_{4} / \mathrm{FTO}+\left[\mathrm{Fe}(\mathrm{CN})_{6}\right]^{3-} \\
& {\left[\mathrm{Fe}(\mathrm{CN})_{6}\right]^{3-} \stackrel{\text { Tip }}{\rightarrow}\left[\mathrm{Fe}(\mathrm{CN})_{6}\right]^{4-}}
\end{aligned}
$$

When the $\left[\mathrm{BiVO}_{4} *\right]$ is in steady state,

$\frac{\partial\left[\mathrm{BiVO}_{4}^{*}\right]}{\partial t}=0=J_{h v} \phi_{h v}\left[\mathrm{BiVO}_{4}\right]-k_{i n j}\left[\mathrm{BiVO}_{4}^{*}\right]$

$\frac{\left[\mathrm{BiVO}_{4}\right]}{\left[\mathrm{BiVO}_{4}^{*}\right]}=\frac{k_{i n}}{J_{h v} \phi_{h v}}$

As for UME current (diffusion limited current) for $\left[\mathrm{Fe}(\mathrm{CN})_{6}\right]^{3-}$ reduction,

$i_{T, \lim }=4 n F D[C] r_{T} I_{T}(L)$

Where $\mathrm{n}=1$, $[\mathrm{C}]$ is the concentration of $\left[\mathrm{Fe}(\mathrm{CN})_{6}\right]^{3-}$, rT is the radius of the $\mathrm{UME}, D$ is the diffusion coefficient.

Steady state for $\left[\mathrm{BiVO}_{4}{ }^{+}\right]$,

$\frac{\partial\left[\mathrm{BiVO}_{4}^{+}\right]}{\partial t}=0=k_{\text {in }}\left[\mathrm{BiVO}_{4}^{*}\right]-k_{1}\left[\left[\mathrm{Fe}(\mathrm{CN})_{6}\right]^{4-}\right]_{s}\left[\mathrm{BiVO}_{4}^{+}\right]$

$\frac{\left[\mathrm{BiVO}_{4}^{*}\right]}{\left[\mathrm{BiVO}_{4}^{+}\right]}=\frac{k_{1}\left[\left[\mathrm{Fe}(\mathrm{CN})_{6}\right]^{4-}\right]_{s}}{k_{\text {in }}}$

Where, $\left[\left[\mathrm{Fe}(\mathrm{CN})_{6}\right]^{4-}\right]_{s}$ represents the concentration of $\left[\mathrm{Fe}(\mathrm{CN})_{6}\right]^{4-}$ adsorbed on the photocatalyst' surface. 1 represents the film thickness of the photocatalyst

According to the mass conservation,

$\left[\mathrm{BiVO}_{4}^{0}\right]=\left[\mathrm{BiVO}_{4}\right]+\left[\mathrm{BiVO}_{4}^{*}\right]+\left[\mathrm{BiVO}_{4}^{+}\right]$

Steady state for $\left[\mathrm{BiVO}_{4}^{0}\right]$,

$$
\begin{aligned}
& {\left[\mathrm{BiVO}_{4}^{0}\right]=\left[\mathrm{BiVO}_{4}^{*}\right]\left(\frac{k_{i n}}{\kappa_{1}\left[\left[\mathrm{Fe}(\mathrm{CN})_{6}\right]^{4-}\right]_{s}}+\frac{k_{i n}}{J_{h v} \phi_{h v}}+1\right)} \\
& {\left[\mathrm{BiVO}_{4}^{*}\right]=\frac{\left[\mathrm{BiVO}_{4}^{0}\right]}{1+\frac{k_{i n}}{k_{1}\left[\left[\mathrm{Fe}(\mathrm{CN})_{6}\right]^{4-}\right]_{s}}+\frac{k_{i n}}{J_{h v} \phi_{h v}}}}
\end{aligned}
$$

The current $i_{k}$ at the surface of photoanode,

$i_{k}=F A n\left(k_{1} l\left[\left[\mathrm{Fe}(\mathrm{CN})_{6}\right]^{4-}\right]_{s}\left[B i V O_{4}^{+}\right]\right)$ 
Where $l$ represents the film thickness of the photocatalyst. A means the effective reaction area $\left(A=\pi r_{T}^{2}\right)$.

According to Bodenstein principle at the steady state,

$k_{\text {in }}\left[\mathrm{BiVO}_{4}^{*}\right]=k_{1}\left[\left[\mathrm{Fe}(\mathrm{CN})_{6}\right]^{4-}\right]_{S}\left[\mathrm{BiVO}_{4}^{+}\right]$

We can infer

$i_{k}=F A l k_{i n}\left[B^{\prime} i V O_{4}^{*}\right]=F A l k_{i n} \frac{\left[\mathrm{BiVO}_{4}^{0}\right]}{1+\frac{k_{i n}}{\kappa_{1}\left[\left[\mathrm{Fe}(\mathrm{CN})_{6}\right]^{4-}\right]_{s}}+\frac{k_{i n}}{J_{h v} \phi_{h v}}}$

$\frac{1}{i_{k}}=\frac{1}{k_{i n}\left[\mathrm{BiVO}_{4}^{0}\right] F A l}+\frac{1}{\left.k_{1}\left[\mathrm{Fe}(\mathrm{CN})_{6}\right]^{4-}\right]_{S}\left[B i V O_{4}^{0}\right] F A l}+\frac{1}{J_{h v} \phi_{h v}\left[\mathrm{BiVO}_{4}^{0}\right] F A l}$

Simplify the equation according to,

$\left(\kappa_{h v, e f f}\right)^{-1}=\left(J_{h v} \phi_{h v}\right)^{-1}+\left(\kappa_{i n}\right)^{-1} \approx J_{h v} \phi_{h v}{ }^{-1}$

$\left(\kappa_{o x}^{\prime}\right)^{-1}=\left(\kappa_{1}\right)^{-1}$

$\frac{1}{i_{k}}=\frac{1}{\kappa_{h v, e f f}\left[\mathrm{BiVO}_{4}^{0}\right] F A l}+\frac{1}{\left.\kappa_{o x}^{\prime}\left[\mathrm{Fe}(\mathrm{CN})_{6}\right]^{4-}\right]_{S}\left[\mathrm{BiVO}_{4}^{0}\right] F A l}$

$\frac{1}{i_{k}}=\frac{1}{J_{h v} \phi_{h v}\left[\mathrm{BiVO}_{4}^{0}\right] F A l}+\frac{1}{\left.k_{o x}^{\prime}\left[\mathrm{Fe}(\mathrm{CN})_{6}\right]^{4-}\right]_{s}\left[\mathrm{BiVO}_{4}^{0}\right] F A l}$

When the $i_{k}$ reaches the limiting substrate current, that is $\left.\left[\mathrm{Fe}(\mathrm{CN})_{6}\right]^{4-}\right]_{s}=$ $\left.\left[\mathrm{Fe}(\mathrm{CN})_{6}\right]^{3-}\right]^{*}$

It can be inferred that

$\frac{1}{i_{k, l i m}}=\frac{1}{J_{h v} \phi_{h v}\left[B_{\left.i V O_{4}^{0}\right] F A l}\right.}+\frac{1}{\left.k_{O x}^{\prime}\left[\mathrm{Fe}(\mathrm{CN})_{6}\right]^{3-}\right]^{*}\left[B i V O_{4}^{0}\right] F A l}$

Normalized limiting substrate current $I_{k}$, lim is as follows,

$I_{k, l i m}=\frac{i_{k, l i m}}{i_{T, \infty}}=\frac{i_{k, l i m}}{\left.4 D F n\left[\mathrm{Fe}(\mathrm{CN})_{6}\right]^{3-}\right]^{*} r_{T}}$

Where $n=1$.

As for

$\frac{1}{I_{S}}=\frac{1}{I_{T, \text { cond }}}+\frac{i_{T, \infty}}{i_{k, \text { lim }}}+\frac{1}{I_{\text {el,lim }}}$

Where $\frac{1}{I_{\text {el, lim }}}=0$, put (Eq. S12), (Eq. S26) into (Eq. S28), we can obtain the following equation

$\frac{1}{I_{S}}=\frac{1}{I_{T, \text { cond }}}+\frac{\left.4 D\left[\mathrm{Fe}(\mathrm{CN})_{6}\right]^{3-}\right]^{*}}{\pi l r_{T} J_{h v} \phi_{h v}\left[\mathrm{BiVO}_{4}^{0}\right]}+\frac{4 D}{\pi l r_{T} k_{o x}^{\prime}\left[\mathrm{BiVO}_{4}^{0}\right]}$

$\frac{1}{I_{S}}=\frac{1}{I_{T, \text { cond }}}+\frac{4}{\pi} \frac{1}{k}$

$k_{e f f}=k \frac{D}{r_{T}}$ 
$\frac{1}{I_{S}}=\frac{1}{I_{T, \text { cond }}}+\frac{4 D}{\pi r_{T}} \frac{1}{k_{\text {eff }}}$

$\frac{1}{I_{S}}=\frac{1}{I_{T, \text { cond }}}+\frac{4 D}{\pi r_{T}}\left[\frac{\left.\left[\mathrm{Fe}(\mathrm{CN})_{6}\right]^{3-}\right]^{*}}{J_{h v} \phi_{h v} l\left[B i V O_{4}^{0}\right]}+\frac{1}{l k_{o x}^{\prime}\left[\operatorname{BiVO}_{4}^{0}\right]}\right]$

$k_{e f f}=\frac{J_{h v} \phi_{h v} l\left[\mathrm{BiVO}_{4}^{0}\right] k_{o x}^{\prime}}{\left.J_{h v} \phi_{h v}+k_{o x}^{\prime}\left[\mathrm{Fe}(\mathrm{CN})_{6}\right]^{3-}\right]^{*}}$

The explanation for $\eta=E_{a p p}-E_{1 / 2}^{o \prime} E_{1 / 2}^{o \prime}=E^{\theta \prime}+\frac{R T}{n F} * \operatorname{In}\left(D_{\left.\mathrm{Fe}(\mathrm{CN})_{6}\right]^{4-} /}\right.$

$D_{\left.\left.\mathrm{Fe}(\mathrm{CN})_{6}\right]^{3-}\right)^{1 / 2}}$

(Eq. S36)

where $\mathrm{R}=8.314\left(\mathrm{~J} \cdot \mathrm{mol}^{-1} \cdot \mathrm{K}^{-1}\right), \quad T=297(\mathrm{~K}), \quad n=1, \quad F=96485\left(\mathrm{C} \cdot \mathrm{mol}^{-1}\right)$,

$D_{\left.\mathrm{Fe}(\mathrm{CN})_{6}\right]^{4-}}=6.65 \times 10^{-6}\left(\mathrm{~cm}^{2} \cdot \mathrm{s}^{-1}\right), D_{\left.\mathrm{Fe}(\mathrm{CN})_{6}\right]^{3-}}=7.6 \times 10^{-6}\left(\mathrm{~cm}^{2} \cdot \mathrm{s}^{-1}\right)$.

So,

$E_{1 / 2}^{o \prime}=E^{\theta \prime}-0.001 \approx E^{\theta \prime}$

(Eq. S37) 
SI-5 Normalized approach curves towards FTO/BiVO 4 and $\mathrm{FTO} / \mathrm{BiVO}_{4} / \mathrm{NiFe}-$ LDH film in dark
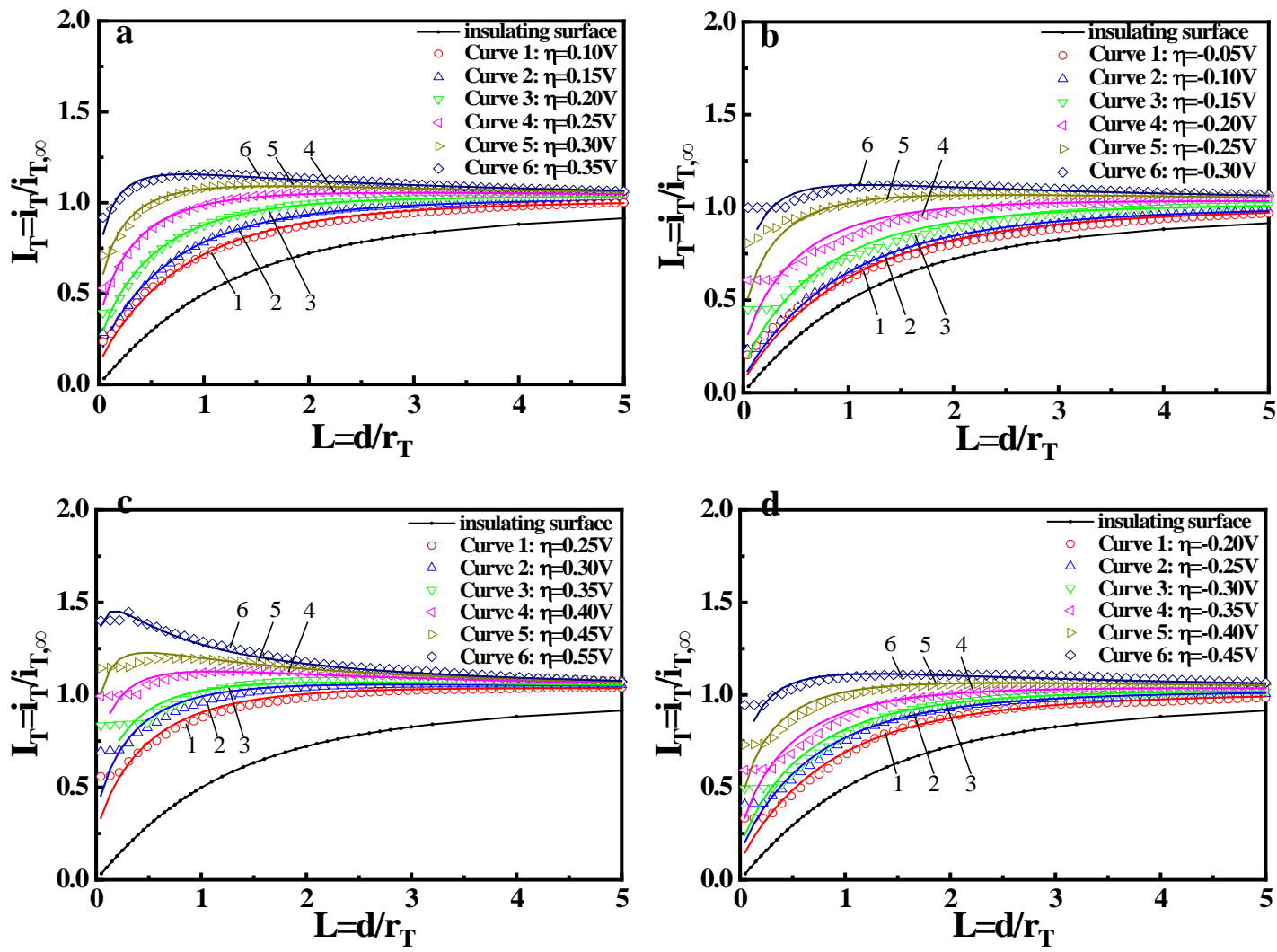

Figure S5. Normalized SECM approach curves in feedback mode with Pt ultramicroelectrode approaching (a) $\mathrm{BiVO}_{4}$ film with $2 \mathrm{mM}\left[\mathrm{Fe}(\mathrm{CN})_{6}\right]^{3-}$; (b) $\mathrm{BiVO}_{4}$ film with $2 \mathrm{mM}\left[\mathrm{Fe}(\mathrm{CN})_{6}\right]^{4-}$; (c) $\mathrm{BiVO}_{4} / \mathrm{NiFe}-\mathrm{LDH}$ film with $2 \mathrm{mM}\left[\mathrm{Fe}(\mathrm{CN})_{6}\right]^{3-}$ and (d) $\mathrm{BiVO}_{4} / \mathrm{NiFe}-\mathrm{LDH}$ film with $2 \mathrm{mM}$ $\left[\mathrm{Fe}(\mathrm{CN})_{6}\right]^{4}$ in dark at different overpotential $\eta\left(=E_{\text {app }}-E_{1 / 2}{ }^{0^{\prime}}\right)$ with a scan rate of $1 \mu \mathrm{m} \cdot \mathrm{s}^{-1}, r_{\mathrm{T}}=12.5$ $\mu \mathrm{m}$. Black solid lines are standard approach curves for insulating substrate (line at the bottom). Note: Six samples were selected and tested in different positions. 
SI-6 Plots of $\ln \left(k_{\text {eff }}\right) \quad$ vs. $\eta$ for the photoanodes for $\mathrm{FTO} / \mathrm{BiVO}_{4}$ and FTO/BiVO 4 /NiFe-LDH film in dark.
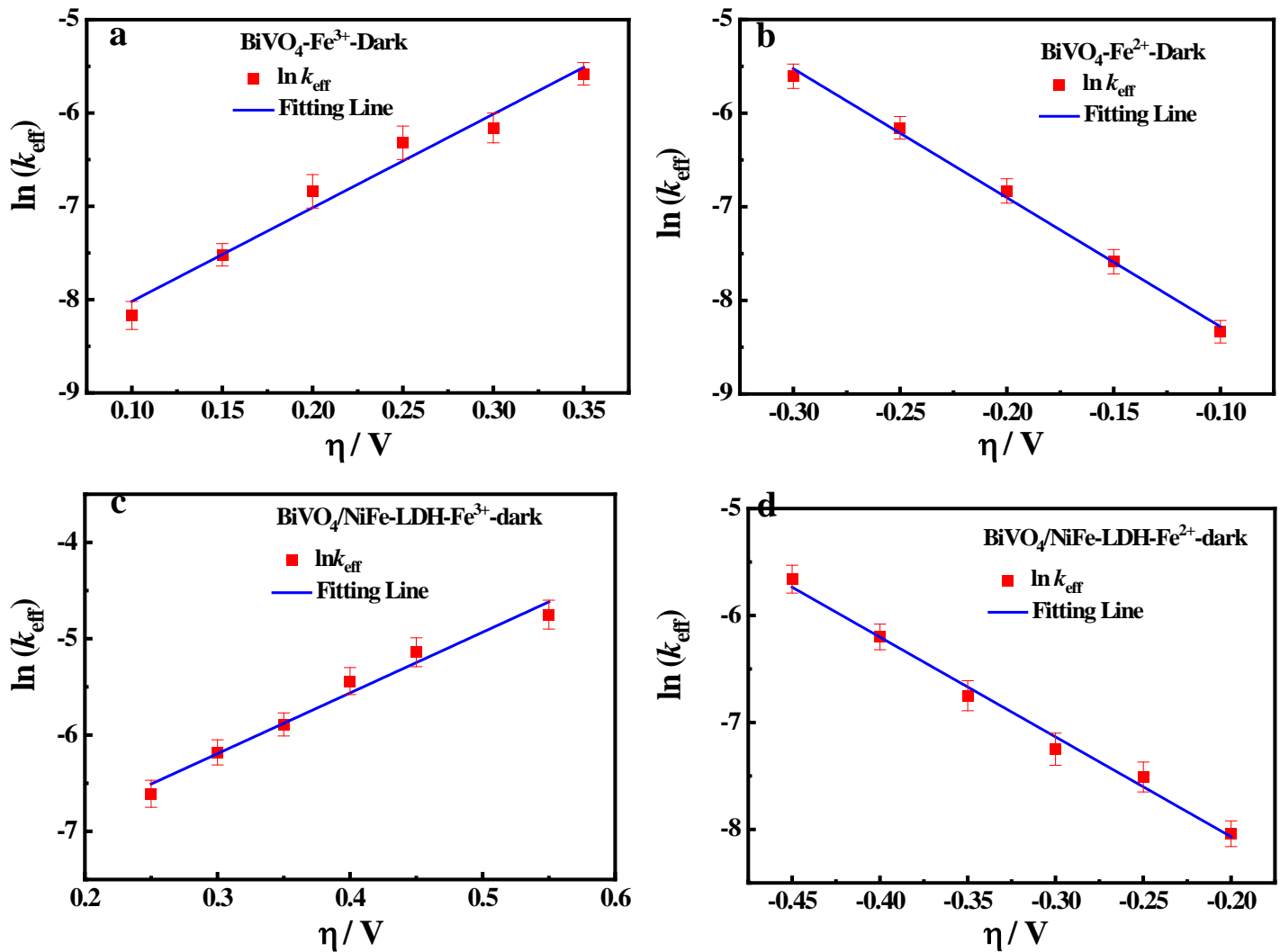

Figure S6. Plots of $\ln \left(k_{\text {eff }}\right)$ vs $\eta$ for the photoanodes (a) $\mathrm{BiVO}_{4}$ with $2 \mathrm{mM}\left[\mathrm{Fe}(\mathrm{CN})_{6}\right]^{3-}$; (b) $\mathrm{BiVO}_{4}$ with $2 \mathrm{mM}\left[\mathrm{Fe}(\mathrm{CN})_{6}\right]^{4-}$; (c) $\mathrm{BiVO} 4 / \mathrm{NiFe}-\mathrm{LDH}$ with $2 \mathrm{mM}\left[\mathrm{Fe}(\mathrm{CN})_{6}\right]^{3-}$; and (d) $\mathrm{BiVO}_{4} / \mathrm{NiFe}-\mathrm{LDH}$ with $2 \mathrm{mM}\left[\mathrm{Fe}(\mathrm{CN})_{6}\right]^{4-}$ in the dark. 


\section{SI-7 Calculated data from SECM measurement}

By fitting the experiment results with SECM theoretical mathematical model (Eqs S1-S5), the apparent normalized rate constant $\kappa$ was obtained, from which the effective first order rate constant $k_{\text {eff }}$ was calculated with the equation $k_{\text {eff }}=\kappa D_{\text {diffusion }} / r_{\mathrm{T}}$, where $D$ is the diffusion coefficient of the redox mediator, $D_{\left.\mathrm{Fe}(\mathrm{CN})_{6}\right]^{4-}}=6.65 \times 10^{-6}\left(\mathrm{~cm}^{2} \cdot \mathrm{s}^{-1}\right)$,

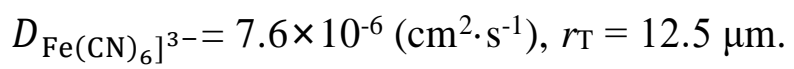


Table S1. Specific data for Figure 3a

\begin{tabular}{|c|c|c|}
\hline$[\mathrm{C}] / \mathrm{mM}$ & $\kappa$ & $k_{\mathrm{eff}} / 10^{-3} \mathrm{~cm} \cdot \mathrm{s}^{-1}$ \\
\hline 2 & 0.186 & 1.01 \\
\hline 1 & 0.367 & 1.99 \\
\hline 0.5 & 0.711 & 3.86 \\
\hline 0.3 & 1.138 & 6.18 \\
\hline
\end{tabular}

Table S2. Specific data for Figure 3b

\begin{tabular}{|c|c|c|}
\hline$[\mathrm{C}] / \mathrm{mM}$ & $\kappa$ & $k$ eff $/ 10^{-3} \mathrm{~cm} \cdot \mathrm{s}^{-1}$ \\
\hline 2 & 0.1608 & 0.873 \\
\hline 1 & 0.3168 & 1.72 \\
\hline 0.5 & 0.6116 & 3.32 \\
\hline 0.3 & 0.9782 & 5.31 \\
\hline
\end{tabular}

Table S3. Specific data for Figure 4a

\begin{tabular}{|c|c|c|c|}
\hline$\eta / \mathrm{V}$ & $\kappa$ & $k_{\text {eff }} 10^{-3} \mathrm{~cm} \cdot \mathrm{s}^{-1}$ & $\ln \left(k_{\mathrm{eff}}\right)$ \\
\hline 0.1 & 0.1973 & 1.2 & -6.725 \\
\hline 0.15 & 0.2056 & 1.25 & -6.685 \\
\hline 0.20 & 0.2444 & 1.46 & -6.53 \\
\hline 0.25 & 0.4168 & 2.53 & -5.98 \\
\hline 0.30 & 0.5233 & 3.18 & -5.75 \\
\hline 0.35 & 0.7011 & 4.26 & -5.46 \\
\hline
\end{tabular}


Table S4. Specific data for Figure 4b

\begin{tabular}{|c|c|c|c|}
\hline$\eta / \mathrm{V}$ & $\kappa$ & $k_{\mathrm{eff}} / 10^{-3} \mathrm{~cm} \cdot \mathrm{s}^{-1}$ & $\ln \left(k_{\mathrm{eff}}\right)$ \\
\hline-0.20 & 0.1911 & 1.01 & -6.898 \\
\hline-0.25 & 0.4650 & 2.46 & -6.01 \\
\hline-0.30 & 0.6751 & 3.57 & -5.635 \\
\hline-0.35 & 0.9074 & 4.80 & -5.34 \\
\hline-0.40 & 1.2393 & 6.55 & -5.028 \\
\hline
\end{tabular}

Table S5. Specific data for Figure 4c

\begin{tabular}{|c|c|c|c|}
\hline$\eta / \mathrm{V}$ & $\kappa$ & $k_{\text {eff }} / 10^{-3} \mathrm{~cm} \cdot \mathrm{s}^{-1}$ & $\ln \left(k_{\text {eff }}\right)$ \\
\hline 0.30 & 0.4320 & 2.63 & -5.94 \\
\hline 0.35 & 0.5238 & 3.18 & -5.75 \\
\hline 0.40 & 0.7265 & 4.42 & -5.42 \\
\hline 0.45 & 0.9224 & 5.61 & -5.18 \\
\hline 0.55 & 1.3321 & 8.10 & -4.82 \\
\hline
\end{tabular}

Table S6. Specific data for Figure 4d

\begin{tabular}{|c|c|c|c|}
\hline$\eta / \mathrm{V}$ & $\kappa$ & $k_{\mathrm{eff}} / 10^{-3} \mathrm{~cm} \cdot \mathrm{s}^{-1}$ & $\ln \left(k_{\mathrm{eff}}\right)$ \\
\hline-0.30 & 0.17 & 0.89 & -7.02 \\
\hline-0.35 & 0.27 & 1.43 & -6.55 \\
\hline-0.40 & 0.43 & 2.30 & -6.08 \\
\hline-0.45 & 0.72 & 3.79 & -5.57 \\
\hline-0.50 & 1.10 & 5.80 & -5.15 \\
\hline-0.55 & 1.57 & 8.27 & -4.79 \\
\hline
\end{tabular}


Table S7. Specific data for Figure S5a

\begin{tabular}{|c|c|c|c|}
\hline$\eta / \mathrm{V}$ & $\kappa$ & $k$ eff $10^{-3} \mathrm{~cm} \cdot \mathrm{s}^{-1}$ & $\ln \left(k_{\text {eff }}\right)$ \\
\hline 0.10 & 0.047 & 0.284 & -8.17 \\
\hline 0.15 & 0.089 & 0.542 & -7.52 \\
\hline 0.20 & 0.176 & 1.07 & -6.84 \\
\hline 0.25 & 0.297 & 1.80 & -6.32 \\
\hline 0.30 & 0.348 & 2.12 & -6.16 \\
\hline 0.35 & 0.619 & 3.76 & -5.58 \\
\hline
\end{tabular}

Table S8. Specific data for Figure S5b

\begin{tabular}{|c|c|c|c|}
\hline$\eta / \mathrm{V}$ & $\kappa$ & $k_{\mathrm{eff}} / 10^{-3} \mathrm{~cm} \cdot \mathrm{s}^{-1}$ & $\ln \left(k_{\mathrm{eff}}\right)$ \\
\hline-0.05 & 0.003 & 0.014 & -11.176 \\
\hline-0.10 & 0.046 & 0.240 & -8.335 \\
\hline-0.15 & 0.096 & 0.507 & -7.587 \\
\hline-0.20 & 0.204 & 1.080 & -6.831 \\
\hline-0.25 & 0.401 & 2.120 & -6.156 \\
\hline-0.30 & 0.695 & 3.676 & -5.606 \\
\hline
\end{tabular}

Table S9. Specific data for Figure S5c

\begin{tabular}{|c|c|c|c|}
\hline$\eta / \mathrm{V}$ & $\kappa$ & $k$ eff $/ 10^{-3} \mathrm{~cm} \cdot \mathrm{s}^{-1}$ & $\ln \left(k_{\mathrm{eff}}\right)$ \\
\hline 0.25 & 0.221 & 1.34 & -6.61 \\
\hline 0.30 & 0.341 & 2.07 & -6.18 \\
\hline 0.35 & 0.457 & 2.78 & -5.89 \\
\hline 0.40 & 0.712 & 4.33 & -5.44 \\
\hline 0.45 & 0.964 & 5.86 & -5.14 \\
\hline 0.55 & 1.423 & 8.65 & -4.75 \\
\hline
\end{tabular}


Table S10. Specific data for Figure S5d

\begin{tabular}{|c|c|c|c|}
\hline$\eta / \mathrm{V}$ & $\kappa$ & $k_{\text {eff }} 10^{-3} \mathrm{~cm} \cdot \mathrm{s}^{-1}$ & $\ln \left(k_{\mathrm{eff}}\right)$ \\
\hline-0.20 & 0.061 & 0.32 & -8.04 \\
\hline-0.25 & 0.104 & 0.55 & -7.51 \\
\hline-0.30 & 0.135 & 0.71 & -7.25 \\
\hline-0.35 & 0.222 & 1.17 & -6.75 \\
\hline-0.40 & 0.386 & 2.04 & -5.20 \\
\hline-0.45 & 0.658 & 3.84 & -5.66 \\
\hline
\end{tabular}




\section{SI-8 Steady-state Photoluminescence measurement}

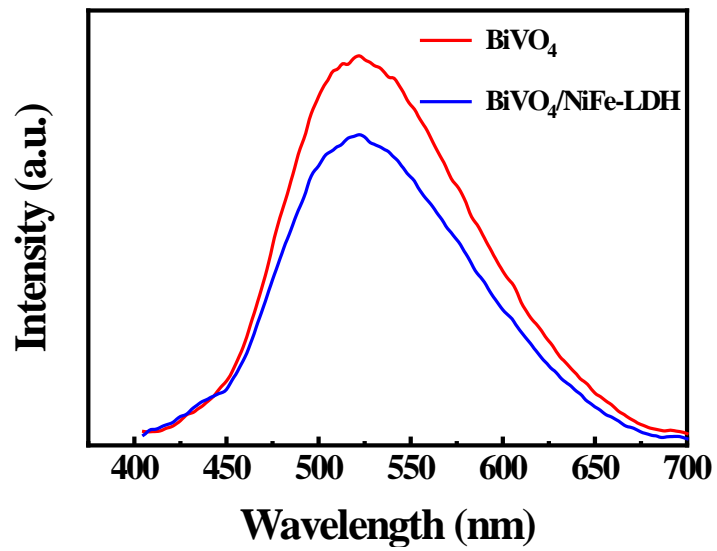

Figure S7. Steady-state photoluminescence spectra of $\mathrm{BiVO}_{4}$ and $\mathrm{BiVO}_{4} / \mathrm{NiFe}-\mathrm{LDH}$.

\section{Reference}

(1) McDonald, K. J.; Choi, K.-S. A new electrochemical synthesis route for a BiOI electrode and its conversion to a highly efficient porous $\mathrm{BiVO}_{4}$ photoanode for solar water oxidation. Energy Environ. Sci., 2012, 5, 8553-8557.

(2) Kim, T. W.; Choi, K.-S. Nanoporous BiVO4 Photoanodes with Dual-Layer Oxygen Evolution Catalysts for Solar Water Splitting. Science 2014, 343, 990-994.

(3) Lv, X.; Xiao, X.; Cao, M.; Bu, Y.; Wang, C.; Wang, M.; Shen, Y. Efficient carbon dots/NiFe-layered double hydroxide/BiVO 4 photoanodes for photoelectrochemical water splitting. Appl. Surf. Sci. 2018, 439, 1065-1071.

(4) Zhong, D. K.; Choi, S.; Gamelin, D. R. Near-Complete Suppression of Surface Recombination in Solar Photoelectrolysis by "Co-Pi” Catalyst-Modified W: BiVO4. J. Am. Chem. Soc. 2011, 133, 18370-18377.

(5) Tsuji, E.; Imanishi, A.; Fukui, K.-i.; Nakato, Y. Electrocatalytic activity of amorphous $\mathrm{RuO}_{2}$ electrode for oxygen evolution in an aqueous solution. Electroch. 
Acta 2011, 56, 2009-2016.

(6) Lefrou, C.; Cornut, R. Analytical Expressions for Quantitative Scanning Electrochemical Microscopy (SECM). ChemPhysChem. 2010, 11, 547-556.

(7) Cornut, R.; Lefrou, C. New analytical approximation of feedback approach curves with a microdisk SECM tip and irreversible kinetic reaction at the substrate. $J$. Electroanal. Chem. 2008, 621, 178-184.

(8) Lefrou, C. A unified new analytical approximation for positive feedback currents with a microdisk SECM tip. J. Electroanal. Chem. 2006, 592, 103-112.

(9) Wei, C.; Bard, A. J.; Mirkin, M. V. Scanning Electrochemical Microscopy. 31. Application of SECM to the Study of Charge Transfer Processes at the Liquid/Liquid Interface. J. Phys. Chem. 1995, 99, 16033-16042. 